\title{
Using Chaid Analysis in Researches and an Application Pertaining to Coping Strategies
}

\begin{abstract}
Murat KAYRI $\dot{I}^{*}$ Murat BOYSAN ${ }^{* * *}$
ABSTRACT: Chaid analysis which combines regression analysis with clustering method is a composite statistical approach. In the study relations between coping strategies, demographical variables and psychological symptoms were appraised by using chaid analysis. On this purpose 329 undergraduates at Yuzuncu Yil University were completed COPE, Short Form of Symptom Check List, and demographical characteristics questionnaire. Data collected from the sample were evaluated by using chaid analysis. Results have shown that using passive coping strategies when encountered with distress precipitates elevations on psychological symptoms. Focus on and venting of emotions, behavioral disengagement, and restraint coping were positively related with increment at general symptoms scores. Demographical characteristics such as age, gender, economical status, and marital status were unrelated with psychological health status.
\end{abstract}

Key Words: Chaid analysis, Coping strategies, Psychological symptoms

\footnotetext{
Asist. Prof. Dr. Yüzüncü Y1l Üniversitesi Eğitim Fakültesi Bilgisayar ve Öğretim Teknolojileri Eğitimi Bölümü mkayri@yyu.edu.tr

*** Res. Asist. Yüzüncü Y1l Üniversitesi Fen Edebiyat Fakültesi Psikoloji Bölümü mbaysan@yyu.edu.tr
} 


\section{SUMMARY}

Purpose and significance: The aim of the study was to introduce an advanced analysis, chaid which is used increasingly in a wide range of studies, by conducting an applied research in education. Recently chaid analysis which is deducing parts from the whole is preferred within the other clustering methods since results and conclusions are obtained on a more precise base as compared to conventional methods. Chaid analysis involves many advantages that multiple regression analyses are performed after the research sample is clustered owing to the dependent variable, maximizing the differences between groups. By this way relations between dependent and independent variables can be appraised in a more sophisticated way. Additionally, the analysis conveys superiority that significant relations between the dependent and independent variables can be seen in a tree diagram. In this study, relations between coping strategies and psychological health were evaluated. Coping is an important factor that impinges on psychological health by regulating emotions and solving problems through the time of stressful life events. Risk factors such as the type of coping behaviors and demographical variables that may give rise to detrimental effects of distress were appraised in a more sophisticated way by using chaid analysis.

Methods: The research was designed to assess the relations between coping strategies, demographical variables, and psychological symptoms among college students. The participants of the study were 206 male and 123 female undergraduate students. 53-item shorter version of Symptom Check List and COPE were completed by the participants. All participants were volunteers recruited from campus area at Yuzuncu Yil University. COPE which is one of the most used instruments in assessing coping strategies, tapping 15 coping strategies in its subscales, was used. Regarding possible risk factors for psychological symptoms, coping strategies and demographical variables such as age, gender, economical status, and marital status were entered in the model. Effects of coping strategies and demographical variables on psychological health were analyzed by using chaid method.

Results: Results have shown that demographical variables have unsubstantial effects on elevations of psychological symptoms. Participant who were less prone to use behavioral disengagement and focus on \& venting of emotions, reported using restraint coping strategies and having more psychological symptoms. Behavioral disengagement was negatively related with focus on and venting of emotions and positively related with elevations on general symptom index scores. Focus on and venting of emotions predicted exacerbation of the symptoms. 
Discussion and Conclusions: Chaid method makes possible to appraise the complex relations between dependent and independent variables by clustering the sample into homogeneous subgroups. Relations between coping strategies, demographical variables and psychological health status have been evaluated in a more sophisticated way by using this method. As a consequence, passive coping strategies such as focus on and venting of emotions, behavioral disengagement, and restraint coping were positively related with elevations on psychological symptoms. 


\title{
Araştırmalarda Chaid Analizinin Kullanımı ve Baş Etme Stratejileri İle İlgili Bir Uygulama
}

\author{
Murat KAYRI' Murat BOYSAN ${ }^{* *}$
}

ÖZ. Chaid analizi, örneklemi sınıflama yöntemiyle (cluster analysis) regresyon analizinin bir arada uygulandığ 1 karma bir istatistiksel yaklaşımdır. Bu çalışmada chaid analizi kullanılarak üniversite öğrencilerinin stresli durumlarda kullandıkları baş etme stratejileri, demografik özellikleri ve psikolojik belirtilerin düzeyi arasındaki ilişkiler değerlendirilmiştir. $\mathrm{Bu}$ amaçla Yüzüncü Y1l Üniversitesi’nde lisans eğitimi almakta olan 329 öğrenciye Baş Etme Tutumlarını Değerlendirme Ölçeği (COPE), Kısa Belirti Listesi (SCL53) ve demografik özellikler soru formu uygulanmıştır. Örneklemden toplanan veriler chaid analizi kullanılarak analiz edilmiştir. Elde edilen bulgular stresli durumlarda pasif baş etme stratejilerinin kullanımının psikolojik belirtilerde artışa neden olduğunu göstermiştir. Duygulara odaklanma ve duyguların dışa vurumu, davranışsal olarak kaçınma ve diğer meşguliyetleri bastırma davranışları psikolojik belirti düzeyiyle ilişkili olan baş etme stratejileridir. Öğrencilerin yaşları, cinsiyeti, medeni durumları, ekonomik düzeyi gibi demografik özelliklerinin psikolojik belirtilerle ilişkili olmadığı gözlenmiştir.

Anahtar Sözcükler: Chaid analizi, Baş etme stratejileri, Psikolojik belirtiler

\footnotetext{
Yrd. Drç. Dr. Yüzüncü Y1l Üniversitesi Eğitim Fakültesi Bilgisayar ve Öğretim Teknolojileri Eğitimi Bölümü mkayri@yyu.edu.tr

Araş. Gör. Yüzüncü Yıl Üniversitesi Fen Edebiyat Fakültesi Psikoloji Bölümü mbaysan@yyu.edu.tr
} 


\section{GİRIS}

Bilimsel geçerliliğinin yüksek olması gerekliliğinden dolayı eğitim bilimlerindeki araştırmaların kuramdan çok, deneysel ağırlıklı olması önemli görülmektedir. Eğitim bilimleri sahasında yapılan nicel ya da nitel ağırlıklı çalışmaların isabetli test istatistiği ile yürütülmüş olması da, oldukça önem arz etmektedir. Rakamları yorumlama sanatı olan istatistik, modelin ve tekniğin yerinde olmaması durumunda elde edilen bulgu ve sonuçların yanlı (biased) olabileceği şüphesini bünyesinde barındırabilmektedir. Bundan dolayı çok hassas olan ve özellikle kuramdan uygulamaya hükmeden eğitim bilimleri alanında ileri düzey istatistik tekniklerinin kullanılması zorunluluk haline gelmektedir. Bu çalışmada yeni sayılabilecek ve eğitim bilimleri araştırmalarında sebep-sonuç ilişkisini oldukça detaylandıran karar ağaçları (Classification tree; decision tree;CR\&T) tekniklerinden chaid (Chi-squared Automatic Interaction Detection) analizi, "sorunlarla baş etme stratejileri" üzerine yapılmış olan deneysel bir uygulama ile birlikte tanıtılmaya çalışı1mıştır.

Eğitim-öğretim sürecinde bireylerin başarılarını etkileyen bir çok etmenden söz edilebilir. Her ne kadar etkileme düzeyleri tartışılsa da, çevre ve kalıtım hayatın her safhasında ögrenmeyi etkileyen temel etmenler olarak kabul edilmektedir. $\mathrm{Bu}$ anlamda, bireyin eğitimi veya belli bir konuda öğrenmesi, hatta uzmanlaşması bir ölçüde bireysel farklılıkların temel alınarak ögretim sürecinde işler hale getirilmesine bağlı olarak değişim gösterecektir (Kayri ve Gökdaş, 2006). Ancak bireyin karşılaştığı sorunlarla baş etmesi ve bu konuda bireyin göstereceği direnç, çoğu problemin çözümünü de beraberinde getirebilecektir.

Baş etme, "kişinin problem çözme yeterliliğini zorlayan veya aşan dışsal ve içsel ihtiyaçlarını yönlendirmekte süreğen olarak benimsediği bilişsel ve davranışsal çabalardır" (Lazarus ve Folkman, 1984: 141). Bilişsel fenomonolojik stres modelinde, baş etme stratejilerinin işlevsel bir tanımlaması yapılmaya çalışılmaktadır. Baş etme stratejileri iki alanda kişilerin psikolojik uyum sağlamaya yönelik çabalarında bir dengeleme mekanizması olarak işlev görmektedir. Bu alanlar, "stresli yaşam olaylarına yönelik uyum mekanizması (probleme yönelik)" ve "duygusal olarak stres düzenleyici (duygulara yönelik)" olarak sinıflanmaktadır (Folkman ve Lazarus, 1980; Folkman ve diğ., 1986). Model, baş etme stratejilerini; sorunla aktif baş etmede kullanılan davranışsal ve bilişsel baş etme mekanizmaları olarak ayrıştırmaktadır (Moss, 2002). Modelde vurgulanan baş etme stratejileri için işlevsel ve işlevsel olmayan ayrımı yapılmadığ 1 halde, sonuçların stresli durumla ilişkili bağlamsal nitelik taşıdığ varsayılmaktadır (Lazarus ve Folkman, 1984; Folkman ve diğ., 1986). 
Duygular, motivasyon durumu ve bilişsel değerlendirmelerle karşılıklı olarak etkileşimli bir süreç içinde şekillenebilmektedirler (Lazarus, 1989). Baş etme biçimi, yaşam olayları karşısında kişilerin yaptıkları değerlendirmelerde aracı rol oynayarak, duygusal tepkilerin ortaya çıkmasına önemli bir etken olmaktadır (Lazarus ve Folkman, 1988). Pek çok araştırmacı baş etme stratejileri konusunda sorunla yüzleşmeyi içeren aktif baş etme veya problemle karşı karşıya gelmekten kaçınmayı içeren kaçınmacı baş etme stratejileri arasında ayrım yapmaktadır (Billings ve Moos, 1981; Roth ve Cohen, 1986). Duygusal veya aktif problem odaklı baş etme stratejileri negatif duygusal içerikle ilişkili stresi düzenleyerek veya alternatif çözümlerin üretilmesine katkıda bulunarak stresin olumsuz etkilerini engelleyebilmektedir. Bununla beraber, kaçıngan baş etme biçimleri stresin olumsuz etkilerini artırarak durumu daha da katlanılmaz bir hale dönüştürebilmektedirler (Seiffge-Krenke ve Klessinger, 2000). Bu anlamda, baş etme stratejileri arasında işlevsel olan ve olmayan ayrımı yapılabilir. İşlevsel baş etme stratejileri problemle aktif olarak baş edebilmek için destek aramak, somut çözüme yönelik davranışlarda bulunmak veya olası çözümleri araştırmak biçiminde olabilir. Yine stresli durumun görmezden gelinmesi ve konuya ilişkin olası çözümlerin araştırılmaması ise işlevsel olamayan stratejiler arasındadır. Araştırmalar stresli durumlarda aktif baş etme stratejilerinin olumlu sonuçlar vermesine karşın (Vitaliano ve diğ., 1987; Holahan ve Moos, 1990; Holahan ve Moos, 1991), kaçınmacı baş etme stratejilerinin uyumu bozucu bir şekilde işlev gördügüne ve olumsuz psikolojik sonuçları olduğuna işaret etmektedir (Rohde ve diğ., 1990; Holahan ve diğ., 2005; Öngen, 2006). Araştırmalar stresli yaşam olayları karşısında kişiler tarafindan benimsenen pasif baş etme stratejilerinin, ergenlerde ve üniversite öğrencilerinde akademik başarıyı olumsuz yönde etkilediğini göstermektedir (Compas ve ark., 2001; Nelson, Dell'Oliver, Koch, Buckler, 2001; Hampel ve Petermann, 2006). Yine pasif baş etme stratejilerinin benlik saygısında düşme, sigara ve alkol kullanımı ve kendine zarar verme davranışıyla ilişkili olduğu görülmektedir (Guinn ve Vincent, 2002; Patterson ve ark., 2004; Park, Armeli, ve Tennen, 2004; McDonald, 2006). Bu çalışmada, üniversite öğrencilerinin stresli olaylar karşısında kullandıkları baş etme stratejilerinin, Kısa Belirti Listesi'nden (SCL-53) elde edilen rahatsızlık ciddiyeti endeksi puanlarındaki artışla ilişkisi değerlendirilmiştir.

Bilimsel araştırmalarda ele alınan örneklemlerin her zaman homojen olması beklenemez. Bu açıdan veri setinin gerekirse homojen alt sinıflara bölünerek doğru tanımlanması ve her alt sınıfla ilgili yansız parametre tahminlemelerinin yapılması, eğitim bilimleri açısından elde edilen bulguların güvenilirliğinin artmasına imkân sağlayacaktır. Ayrıca, bilimsel çalışmalardaki önemli istatistiksel konulardan biri, üzerinde durulan olayı önemli derecede etkileyen faktörlerin yanı sıra, bu faktörlerin hangi 
seviyesindeki etkinin yüksek olduğunu belirlemektir (Doğan ve Özdamar, 2003). Bağımlı değişkenlerdeki değişimi önemli derecede etkileyen faktörleri irdeleyen chaid analizi, model içerisinde yer alan değişkenlerin etkileşim ve genel olarak ortak düzeydeki kombinasyonlarını da tespit etmeye çalışmaktadır (Doğan ve Özdamar, 2003).

Bilindiği üzere tanımlayıcı istatistikler evren hakkında kısa özetler sunarken; süreç içerisinde yaşanabilecek değişimler hakkında araştırmacıya bir ön bilgi vermektedir. Buna karşın, analitik istatistiksel yöntemlerde kurulan model ile bir regresyon denklemi elde edilebilmektedir. Genel anlamda regresyon, modelde mevcut değişkenlerin ilişki yapılarını, bağımsız değişkenlerin bağımlı değişken üzerindeki teferruatlı etkilerini araştırmacıya bir tahminleme metodu olarak sunmayı hedeflemektedir (Erar, 1985).

İnceleme altına alınan örneklem büyüklügünün fazla olduğu durumlarda; evren içerisindeki homojenlik ilkesinin ihlalinden dolayı, gelişigüzel kurulan bir regresyon modeline ait tahminleme (estimation) gerçeği yansıtmayabilir. Bundan dolayı bütünü parçalara bölmek ve sınıflandırılmış olası alt gruplar ile incelemeyi sürdürmek daha gerçekçi bir zemin oluşturabilmekte ve bu yolla istatistikte önemsenen homojenlik şartı da yerine gelebilmektedir. Yine bilindiği üzere, klasik regresyon denkleminde (parametrik durumlar için) normallik, doğrusallık, homojenlik ve toplanabilirlik gibi varsayımlar gerçekleşmeden bir analizin yapılması mümkün olamamaktadır (Efe ve diğ., 2000). Bu anlamda chaid analizi ile elde edilecek bir regresyon denklemi, bilinen klasik varsayımlardan muaf tutulmaktadır. Çünkü güçlü bir öteleme algoritması (iteration algorithm) ile bütün olan evren kararlı alt dügümlere (node) bölünebilmektedir. Bu işlem beraberinde, verilerin dağılımında normalliği ve homojenliği sağlayabilmektedir. Yine aynı şekilde chaid analizi sürekli ve kategorik verileri, aynı anda modele alabilmeye olanak tanımaktadır. Bu nedenle chaid analizi parametrik ve parametrik olmayan ayrımını kaldırmakta, yöntem algoritmasında istatistiksel olarak yarı parametrik (semi-parametric) özellik taşımaktadır.

Genel anlamda karar ağaçları, bağımsız değişkenleri aşamalı olarak (progressively) olası küçük gruplara bölebilen doğrusal olmayan bir ayırma (non-linear discrimination) metodu olarak düşünülmektedir (Türe ve diğ., 2006). Karar ağaçlarının çalışma mekanizması, bölmüş olduğu ağacın her dalında (branch) öteleme (iterasyon) algoritmaları ile bağımlı değişken üzerinde etkili olan bağımsız değişkenlerin en güçlü etkileşimini modelleme üzerine kuruludur (Michael ve Gordon, 2004; Ho ve diğ., 2004; Türe ve diğ., 2005). Karar ağaçlarından biri olan chaid analizi, bütün olan veri setini tekrarlı olarak iki ya da ikiden fazla dügüümlere (node) ayıran etkili bir teknik olarak düşünülmektedir (Michael ve Gordon, 2004; Ho ve diğ., 2004; Türe ve diğ., 2005). Ayrıca chaid analizi, özellikle bağımsız değişkenlerin 
birbirleriyle olan ilişki ve etkileşimlerini konu edindiği için ki-kare $\left(\chi^{2}\right)$ istatistiğini kullanmaktadır. Bilindiği üzere ki-kare test istatistiği, değişkenler arasındaki bağımlılığı ele almaktadır. Bu özelliğinden dolayı chaid analizinin matematiksel olarak ki-kare tabanında modeller kurmas1 önemli bir tutarlılığı beraberinde getirmektedir. Yine bu çalışmadaki gibi ele alınan baş etme stratejilerine yönelik alt ölçekler ve örnekleme ait demografik verilerin bağımlı değişken üzerindeki etkilerini bir bütün olarak değerlendirmede, bu analiz önemli avantajlar taşımaktadır. İlişki tabanlı bir model ( $\chi^{2}$ gibi) doğrultusunda bu tür ölçeklerin ilgili test istatistiklerine (chaid gibi) tabi tutulması yansız ve doğru (robust) sonuçları yakalayabilme şansını artırabilmektedir.

Bağımlı değişkenin kategorik var-yok (0-1; binary) olduğu durumlarda kullanılan lojistik regresyon tekniği ile modellemeler yapılıp, modele ilişkin risk faktörleri (odds ratio) de tahminlenebilmektedir (Hair ve diğ., 1998). Chaid analizinde ise, bunun yapılabilme gücünün daha yüksek olduğu bildirilmektedir (Türe ve diğ., 2005). Çünkü chaid analizinde bağımsız değişkenlerin en üst düzeydeki etkileşimlerini modele alan algoritma sayesinde, benzer özellikleri taşıyan karakterler aynı homojen dügümlere taşınmaktadır. Böylece, elde edilen karar ağacında bütün detaylar net bir şekilde izlenebildiği gibi, elde edilen regresyon denklemine ait parametrelerin de daha güvenilir sonuçlar vermesi beklenmektedir.

Chaid analizinin dışında sınıflandırma ya da ağaç şeklinde hiyerarşik diyagram modelleri kuran diğer teknikler ise: "Sınıflandırma ve Regresyon Ağaçları (Classification and Regression Trees; C\&RT)" ve "Hızl1-YansızEtkili-İstatistik Ağacı (Quick-Unbiased-Efficient-Statistical Tree; QUEST)" şeklindedir (Doğan ve Özdamar, 2003'den alıntı; SPSS Inc, 1998). Chaid analizinde bağımlı ve bağımsız değişkenlerin tipi model kurma aşamasında bir sınırlılık getirmediği halde, C\&RT ve QUEST sinıflandırma teknikleri ise, chaid analizinden farklı olarak ele alınan değişken türlerine (kategorik, sınıflama, sıralama) bir sinırlılık getirmektedir. Bu yönüyle chaid analizi, önemli avantajlara sahiptir (Ratner, 2000).

\section{YÖNTEM}

\section{Örneklem}

Çalışmaya Yüzüncü Yıl Üniversitesi'nde lisans eğitimi almakta olan, 206's1 (\%62.61) erkek ve 123'ü (\%37.39) kı olmak üzere, toplam 329 öğrenci katılmıştır. Örneklemde yer alan öğrencilere ait bir takım sosyodemografik veriler elde edilmiştir. Bu grupta yer alan kız öğrencilerin yaş ortalaması $20.48(\mathrm{~S}=2.26)$ ve erkek öğrencilerin yaş ortalaması ise 22.05 ( $\mathrm{S}=4.74)^{\prime}$ 'dir. Öğrenciler tabakasız gelişigüzel örnekleme yöntemine göre seçilmiştir. Örneklemin \%89.4'ü $(n=294)$ bekâr, \%5.5'si $(n=18)$ evli ve \%0.3'u (n=1) boşanmış olduklarını bildirmiştir. 16 kişi bu soruya cevap 
vermemiştir. Ekonomik durumlarıyla ilişkili olarak, deneklerin \%8.8'i $(n=29)$ alt, \%68.7'si $(n=226)$ orta ve $\% 17.3$ 'ü $(n=57)$ üst sosyo-ekonomik gruptan olduklarını belirtmişlerdir. 17 kişi de bu soruya cevap vermemiştir.

\section{Araçlar}

Kısa Belirti Listesi (SCL-53): Ölçeğin orijinal formu Derogatis (1992) tarafından geliştirilmiştir. 53 maddeden oluşan, 0-4 arasında puanlanan likert tipi bir ölçektir. Kısa Belirti Listesi 10 alt ölçeğin yanı sıra, "Rahatsızlık Ciddiyeti Endeksi" olarak adlandırılan genel bir puan da vermektedir. Türkçe formun alt ölçeklerinin iç tutarlılık katsayıları $0.71-0.85$ arasında değişmektedir. Türk örneklemindeki geçerlilik ve güvenilirlik çalışması Şahin ve Durak (1994) tarafından yapılmıştır.

Baş Etme Tutumlarını Değerlendirme Ölçeği (COPE): Stresli durumlar karşısında kullanılan başa çıkma stratejilerini belirlemek için Carver, Scheier ve Weintraub (1989) tarafından geliştirilmiştir. Türkçe formunun geçerlilik ve güvenilirlik analizi Ağargün ve diğ. (2005) tarafından yapılmıştır. Türkçe formunun iç tutarlılık katsayısı 0.79 , ölçeğin alt ölçekleri ve toplam puanlar arasındaki bağıntı geçerliliği 0.29 ve 0.76 arasında değişmektedir. COPE ölçeği, kendi içerisinde 15 alt ölçekten oluşmaktadır: Pozitif yeniden yorumlama ve gelişme, zihinsel boş verme, duygulara odaklanma ve duyguları açığa vurma, yararlı sosyal destek kullanımı, aktif baş etme, inkâr, dini olarak baş etme, şakaya vurma, davranışsal olarak kaçınma, geri durma, duygusal sosyal destek kullanımı, madde kullanımı, kabullenme, diğer meşguliyetleri bastırma, plan yapma. Her bir alt ölçekten alınabilecek puanlar 4 ve 16 puan arasında değişmektedir.

\section{İşlem}

Örneklemdeki bireylere uygulanan ölçek ve alt ölçeklere ait maddeler puanlanmış ve veri setine ilgili ölçek maddelerine ilişkin puanlar girilmiştir. Örneklemdeki bireylerin sorunlarla baş etme stratejilerinin belirlenmesi ve sonucu etkileyen değişkenlerin sınıflandırılması (düğümler halinde) chaid analizi ile yapılmıştır.

\section{BULGULAR}

Yöntem kısmında belirtilen veri setine uygulanan ölçek (Rahatsızlık Ciddiyeti Endeksi;RCE) ve alt-ölçeklere ait puanlamalar chaid analizine tabi tutularak sınıflandırılmıştır. RCE ile baş etme stratejileri arasındaki ilişki, chaid analizi ile belirlenmeye çalışılmıştır. Chaid analizinin uygulanmasından sonra ilgili değişkenler arasındaki ilişki düğümler şeklinde sınıflandırılmış olup, elde edilen diyagram, şekil 1'de gösterilmiştir. 
Rahatsızlık Ciddiyeti Endeksi (RCE)

\begin{tabular}{|ll|}
\hline \multicolumn{1}{|c|}{ Düğ̈̈m 0 } \\
Ortalama & $: 1.124$ \\
Ss & $: 0.623$ \\
$\mathrm{n}$ & $: 322$ \\
Yüzde ( \%) & $: 100$ \\
& \\
\hline
\end{tabular}

Duygulara Odaklanma ve Duyguları Açığa Vurma $P=0.000, \quad F=27.986$ $S d 1=1, \quad S d 2=320$

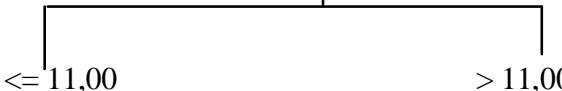

\begin{tabular}{|ll|}
\hline \multicolumn{3}{|c|}{ Düğüm 1 } \\
Ortalama & $: 0.976$ \\
Ss & $: 0.593$ \\
$\mathrm{n}$ & $: 189$ \\
Yüzde (\%) & $: 58.7$ \\
\multicolumn{2}{|c|}{} \\
\hline
\end{tabular}

11,00

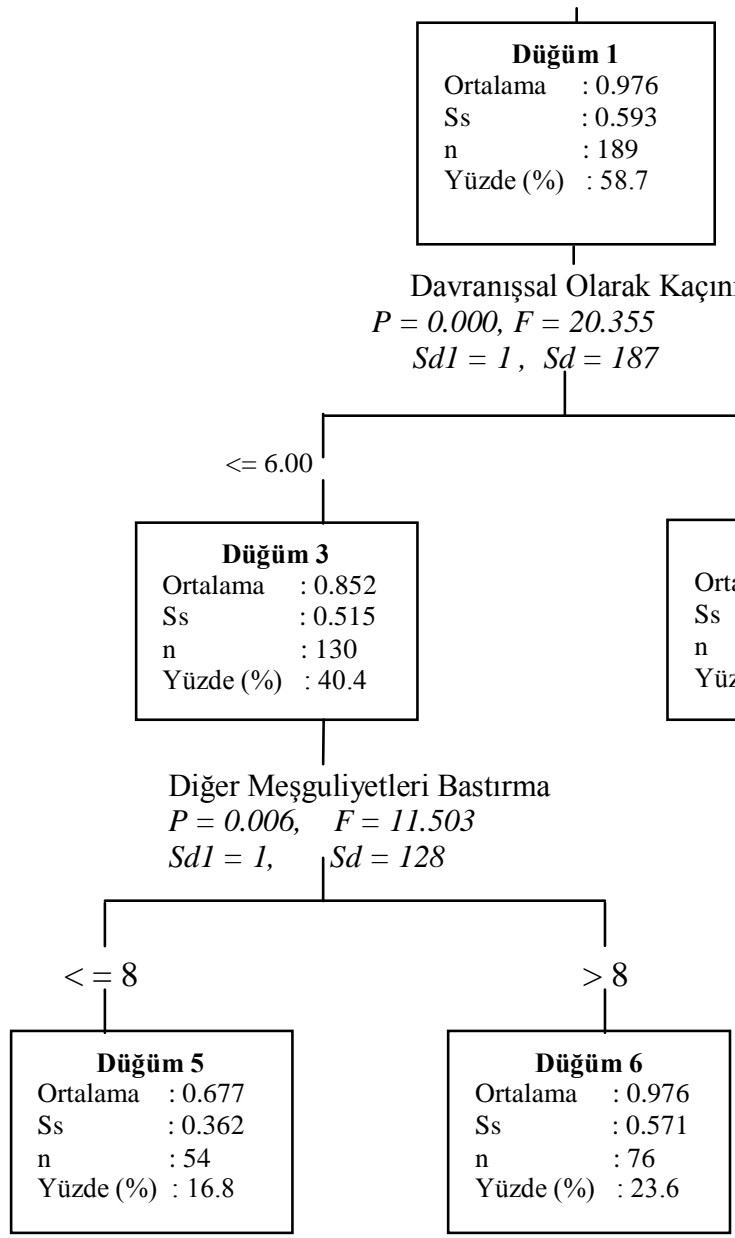

Şekil 1. Rahatsılılk ciddiyeti endeksiyle baş etme stratejileri arasındaki ilişkiyi gösteren CHAID analizi şemasl 
Şekil 1 incelendiğinde, Rahatsızlık Ciddiyeti Endeksi'nin bağımlı değişken olduğu modelde, katılımcıların Baş Etme Tutumları Ölçeğinde yer alan 15 baş etme stratejisinden aldıkları puanlar bağımsız değişken olarak alınmıştır. Bunun yanı sıra, deneklerin yaşı, cinsiyeti, ekonomik durumu ve medeni durumu da baş etme stratejileriyle birlikte bağımsız değişkenler olarak modele dahil edilmiştir. Chaid analizinde, ilk basamakta yapılan aşamalı (stepwise) regresyon analizi sonucuna bakılmaktadır. $\mathrm{Bu}$ analiz sonucunda bağımlı değişken üzerine etkisi istatistiksel olarak önemli bulunan bağımsız değişkenler içinde en yüksek $F$ değerine sahip olan değişken, chaid diyagramında ilk sırayı almaktadır. Bu çalışmada duygulara odaklanma ve duyguları açığa vurma davranışının, psikolojik bulguların ortaya çıkmasıyla en çok ilişkili baş etme stratejisi olduğu görülmüştür. $\mathrm{Bu}$ nedenle söz konusu değişken chaid analizi şemasında ilk sırayı almıştır. Sonrasında bağımlı değişkenle ilişki düzeyi en yüksek olan bağımsız değişken ( $F$ değerinin büyüklüğüne göre), bağımlı değişkendeki varyasyona göre gruplar arası farkları en yükseğe çıkaracak şekilde sınıflama (classifying) analiziyle düğümlenmektedir. Söz konusu basamaktaki son işlem ise bağımlı değişkene göre gruplar arasında varyans analizinin yapılmasına dayalı olmaktadır. Şekil 1' de görüleceği gibi, RCE puanlarına göre öğrenciler iki alt grupta kümelenmiştir. Yapılan sınıflama analizi sonucunda chaid analizi şemasında ilk basamağa alınan bağımsız değişken için kesme puanları belirlenmektedir. Duygulara Odaklanma ve Duyguları Açığa Vurma alt ölçeğinden alınabilecek en düşük puan 4 ve en yüksek puan da 16' dir. RCE puanlarına göre yapılan sınıflama analizi sonucunda, Duygulara Odaklanma ve Duyguları Açığa Vurma alt ölçeğinden 11 puanın üzerinde alan 133 kişi bu baş etme stratejisini çok kullanan grubu ve 11 puan dahil olmak üzere bu puanın altında alan 189 kişi ise diğer grubu oluşturmuştur. Bu iki grup Dügüum 1 ve Dügüm 2'yi oluşturmaktadır. Sorunlar karşısında duygulara odaklanma ve duyguları açığa vurma davranıșını daha çok gösteren öğrencilerin rahatsız ciddiyeti endeksi puanlarının istatistiksel olarak önemli düzeyde yüksek olduğu görülmüştür $\left(\mathrm{F}_{(1,320)}=27.986 ; p<0.01\right)$. Chaid şemasında ikinci basamaktaki dügümler oluşturulurken, bağımsız değişkenlerin bağımlı değişkenle olan ilişkisi birinci düğümde sınıflanmış olan iki grupta ayrı bir şekilde analiz edilmektedir. Bağımlı değişkenle istatistiksel olarak önemli ve en yüksek düzeyde ilişkili ikinci bağımsız değişken her bir düğüm için modele alınmaktadır. Daha sonra ilk dügümünde yer alan istatistiksel işlemler tekrarlanmaktadır. $\mathrm{Bu}$ çalışmada RCE puanlarıyla Davranışsal Olarak Kaçınma alt ölçeği arasındaki ilişki, ilk düğümde Duygulara Odaklanma ve Duyguları Açığa Vurma alt ölçeğinden 11 puan ve altında alan grupta istatistiksel olarak önemli bulunmuştur. Bir diğer anlatımla duygulara odaklanma ve duyguları açığa vurma stratejisini daha az kullananların aynı zamanda davranışsal olarak kaçınma baş etme stratejisini de daha az 
kullandıkları anlaşılmaktadır. Sonraki aşamada, ilk düğümde Duygulara Odaklanma ve Duyguları Açığa Vurma alt ölçeğinden 11 puan ve altında alan 189 kişinin RCE puanlarına göre sınıflama analizi yapılmıştır. Yapılan sınıflama analizi sonucunda chaid şemasında ikinci aşamada analize alınan 189 kişi için RCE puanları arasındaki farkı en yükseğe çıkarabilen iki grup elde edilmiştir. Analiz, ikinci sırada yer alan 189 kişilik örneklemi iki gruba ayırdıktan sonra, RCE puanlarıyla en yüksek düzeyde ilişkili olduğunu bulduğu Davranışsal Olarak Kaçınma alt ölçeği için kesme puanları hesaplanmıştır. Davranışsal Olarak Kaçınma alt ölçeğinden altı puan ve altında alan 130 kişi birinci grubu ve altı puanın üzerinde alan 59 kişi ise diğer grubu oluşturmuştur. $\mathrm{Bu}$ iki grup Dügü̈m 3 ve Düğüm 4'ü oluşturmuştur. Duygulara Odaklanma ve Duyguları Açığa Vurma baş etme stratejisini daha az kullandığı halde, Davranışsal Olarak Kaçınma baş etme stratejisini daha fazla tercih eden katılımcıların psikolojik belirti puanlarının önemli düzeyde yüksek olduğu anlaşılmaktadır $\left(\mathrm{F}_{(1,187)}=20.355 ; p<0.01\right)$. Davranışsal Olarak Kaçınma alt ölçeğinden düşük puan alan 54 kişilik grupta,, Diğer Meşguliyetleri Bastırma baş etme stratejisi RCE puanlarıyla ilişkili bulunmuştur.. Davranışsal Olarak Kaçınma alt ölçeğinden düşük puan alan 130 kişi arasında yapılan sınıflama analizi sonucunda, bu ölçekten sekiz puan ve altında alan 54 kişi birinci grubu, sekiz puanın üzerinde alan 76 kişi ise ikinci grubu oluşturmuştur. Bu iki grup Düğüm 5 ve Dügüm 6'y1 oluşturmuştur. Bu iki grup arasında Diğer Meşguliyetleri Bastırma baş etme stratejisini daha çok kullanan 76 kişinin RCE puanları diğer gruba oranla önemli düzeyde yüksektir $((\mathrm{F}(1,128)=11.503 ; p<0.01)$. Analize alınan değişkenlerin dişında diğer 12 baş etme stratejisi ve demografik özellikler, psikolojik bulgulardaki artışla ilişkili bulunmadığı için modelde yer almamiştır.

\section{TARTIŞMA ve SONUÇ}

Kişilerin kullandıkları stresle baş etme stratejileri pek çok psikolojik değişkeni etkileyen bir unsurdur. Stresli durumlarda benimsenen baş etme stratejileri, olumsuzlukları azaltıcı -işlevsel- rol oynayabildiği gibi stresi artırıcı yönde de -işlevsel olamayan- şekliyle öngörülmektedir (SeiffgeKrenke ve Klessinger, 2000). Bu çalışmada Yüzüncü Yıl Üniversitesi öğrencilerinin stresle baş etme biçimlerinin psikolojik belirtilerle ilişkisi CHAID analizi kullanılarak değerlendirilmiştir. Bu amaçla Baş Etme Tutumları Değerlendirme Ölçeği'nde yer alan 15 baş etme stratejisinin Kısa Belirti Listesi'nden elde edilen Rahatsılık Ciddiyeti Endeksi puanlarıla ilişkisi araştırılmıştır.

Elde edilen bulgular demografik verilerin (yaş, cinsiyet, medeni durumları, ekonomik düzey gibi) psikolojik belirtilerdeki artışa istatistiksel olarak önemli bir etkisinin olmadığını göstermiştir. Öğrencilerin stresli durumlarla baş etmede kullandıkları davranışsal mekanizmalardan pasif baş 
etme stratejilerinin psikolojik belirtiler endeksi puanlarındaki artışla ilişkili olduğu görülmüștür. Sonuçlar literatür bulgularıyla uyumludur (Rohde ve diğ., 1990; Holahan ve diğ., 2005; Öngen, 2006). Bununla beraber araştırmalar, aktif baş etme stratejilerine göre pasif stresle baş etme stratejilerinin çok daha kararlı özellik gösterdiğini bildirmektedirler (Fleishman, 1984; Folkman ve diğ., 1986). Stresli durumlarda duygusal olarak dışa vurum ve duygulara odaklanma davranışının artmış psikolojik belirtilerle ilişkili olduğu görülmüştür. Davranışsal olarak kaçınma stratejileri duygusal baş etme stratejisi ile negatif yönde ve psikolojik belirtilerdeki artışla pozitif yönde ilişkilidir. Diğer meşguliyetleri bastırma davranışı, davranışsal kaçınma ve duygusal dışa vurum davranışlarının daha az tercih edilmesiyle ilişkilidir. Bununla beraber diğer meşguliyetleri bastırmak psikolojik belirtilerdeki artışa neden olmaktadır. Sonuç olarak, diğer meşguliyetlerine ara vererek probleme odaklanmayı tercih eden katılımcılar, davranışsal olarak kaçınma davranışını ve duygularına odaklanan ve duygularını açığa vurmayı sorunlarla baş etme yöntemi olarak daha az tercih etmektedirler. Karşılaştıkları sorunlar karşısında söz konusu baş etme stratejilerini daha fazla tercih eden katılımciların Rahatsızlık Ciddiyeti Endeksi puanlarının önemli düzeyde yükseldiği bulunmuştur.

Sınıflama tekniği dışındaki klasik regresyon analizinde veri seti tek bir örneklem grubu olarak ele alınmaktadır. Bu klasik yöntemlerde uç değerler dikkate alınamamakta ve bu değerler normal dağ 11 เm eğrisinde örneklem ortalaması içinde ifade edildiği biçimiyle analize alınmaktadır. $\mathrm{Bu}$ da aslında bazı tahminlemelerin yanlı olabileceği sonucunu doğurmaktadır. Sınıflandırma (classification) metotları son zamanlarda bütünden parçalara ulaşıp bulgu ve yorumu doğru bir zemine yerleştirme adına sık kullanılan ve özellikle tercih edilen bir istatistik yöntem olarak düşünülmektedir. $\mathrm{Bu}$ anlamda, chaid analizi sahip olduğu algoritma avantajı ve analiz bulgularını herkesin kolay bir şekilde yorumlayabileceği diyagram (ağaç) şeklinde sunma gibi özelliklerinden dolayı tercih edilmektedir (Michael ve Gordon, 2004; Ho ve diğ., 2004; Türe ve diğ., 2005). Yapılan analizden anlaşılabileceği üzere chaid analizi içinde bağımlı değişkenle ilişkili değişkenlerin hiyerarşik düzende bir sıralaması yapılırken, analiz içinde sınıflama yöntemi kullanılarak, her bir aşamada örneklem olabilecek en homojen alt gruplara indirgenmektedir. $\mathrm{Bu}$ durum örneklemden evren değerlerine en yakın sonuçların elde edilmesine olanak tanımaktadır.

Chaid analizinde, ilk basamakta yapılan aşamalı (stepwise) regresyon analizi sonucu; bağımlı değişken ile en çok ilişkili olan bağımsız değişkenler dügümler oluşturmaktadır. İlişkisi en çok tespit edilen düğümlere ait $\mathrm{F}$ değeri diğer düğümlere göre yüksek elde edilmektedir. Bu da bağımlı değişken ile en çok ilişkili olan değişkenlerin bir göstergesi olarak ortaya 
çıkmaktadır. Bu doğrultuda, chaid analizindeki karar ağacının altında oluşan düğümler bir anlamda değişkenlerin önem sırasını da belirlemektedir.

Elde edilen bulgulardan yola çıkarak, pek çok alanda kullanım olanağı sağlayan karar ağaçları içinde yer alan chaid analizinin eğitim bilimleri ile ilgili araştırmalar için de verimli bir şekilde kullanılabileceği düşünülebilir. Ayrıca bu istatistiksel metot kullanılarak, özellikle heterojen veri setlerinde, homojen düğümlerin (node) oluşturulması, elde edilecek olan bulguların gerçeği daha sağlam ve yansız gösterebileceği de söylenebilir. 


\section{KAYNAKLAR}

Ağargün, M.Y., Beşiroğlu, L., Kıran, Ü.K., Özer, Ö.A., Kara, H. (2005). COPE (Baş Etme Tutumlarını Değerlendirme Ölçeği): Psikometrik Özelliklere İlişkin Bir Ön Çalışma. Anadolu Psikiyatri Dergisi, 6, 221226.

Billings, A. G., \& Moos, R. H. (1981). The role of coping responses and social resources in attenuating the stress of life events. Journal of Behavioral Medicine, 4, 157-189.

Carver, C. S., Scheier, M.F., Weintraub, J.K. (1989). Assessing coping strategies: A theoretically based approach. J Pers Soc Psychol 1989, 56, 267-283.

Compas, B.E., Connor-Smith, J.K., Saltzman, H., Thomsen, A.H., \& Wadsworth, M.E. (2001). Coping with stress during childhood and adolescence: Problems, progress, and potential in theory and research. Psychol Bull., 127(1), 87-127.

Derogatis, L.R. (1992). The Brief Symptom Inventory (BSI): Administration, scoring and procedures manual. II. Clinical Psychiatric Research Inc.

Doğan, N., Özdamar, K. (2003). Chaid Analizi ve Aile Planlaması ile İlgili Bir Uygulama. T Klin Tip Bilimleri 2003, 23, 392-397.

Efe, E., Bek, Y., Şahin, M. (2000). SPSS'te Çözümleri ile İstatistik Yöntemler II. Kahramanmaraş: Kahramanmaraş Sütçü İmam Üniversitesi Rektörlüğü, yayın no:10.

Erar, A. (1985). Bağlanım (Regresyon) Çözümlemesi Ders Notları.Ankara: Hacettepe Üniversitesi Fen Fakültesi İstatistik Bölümü.

Fleishman J. A. (1984). Personality characteristics and coping patterns. Journal of Health and Social Behavior, 25, 2, 229-244.

Folkman, S., \& Lazarus, R. S. (1980). An analysis of coping in a middle aged community sample. Journal of Health and Social Behavior, 21, 219-239.

Folkman, S., Lazarus, R., Gruen, R., \& DeLongis, A. (1986) Appraisal coping, health status, and psychological symptoms. Journal of Personality and Social Psychology, 50, 571-579.

Guinn, B., \& Vincent, V. (2002). Determinants of coping responses among Mexican American adolescents. J Sch Health, 72(4), 152-156.

Hair, JF., Anderson, Re., Tahtam, RL., \& Black, WC. (1998). Multivariate data analysis. Englewood cliffs, NJ: Prentice-Hall. 
Hampel, P., \& Petermann F. (2006). Perceived stress, coping, and adjustment in adolescents. J Adolesc Health., 38(4), 409-415.

Ho, S., Jee, S., Lee, J., \& Park, J. (2004). Analysis on risk factors for cervical cancer using induction technique. Expert Systems with Applications, 27, 97-105.

Holahan C. J., Moos, R. H., Holahan, C. K., Brennan P. L., \& Schutte, K. K. (2005). Stress generation, avoidance coping, and depressive symptoms: A 10-year model. Journal of Consulting and Clinical Psychology 2005, 73(4), 658-666.

Holahan, C. J., \& Moos, R. H. (1990). Life stressors, resistance factors, and psychological health: An extension of the stress-resistance paradigm . Journal of Personality and Social Psychology, 58, 909-917.

Holahan, C. J., \& Moos, R. H. (1991). Life stressors, personal and social resources, and depression: A 4-year structural model. Journal of Abnormal Psychology, 100, 31-38.

Kayri, M., Gökdaş, İ. (2006). Karışımlı Model Analiz Tekniğinin Eğitim Bilimleri Araştırmalarında Uygulanabilirliği Üzerine Bir Araştırma Örneği. Kuram ve Uygulamada Ĕgitim Bilimleri Dergisi, 6(3), 753-778.

Lazarus R. S. (1989). Constructs of the mind in mental health and psychotherapy. In A. Freeman, K.M. Simon, L. E. Beutler \& H. Arkowitz (Eds), Comprehensive handbook of cognitive therapy (pp. 99121). New York, L.: Plenum Press.

Lazarus, R. S., \& Folkman, S. (1984). Stress, appraisal, and coping. New York: Springer.

Lazarus, R. S., \& Folkman, S. (1988). Coping as a mediator of emotion. Journal of Personality and Social Psychology, 54(3), 466-475.

McDonald, C. (2006). Self-mutilation in adolescents. J Sch Nurs., 22(4), 193-200.

Michael, J., \& Gordon, S. (2004). Data mining technique for marketing, sales and customer support ( $2^{\text {nd }}$ Ed.). New York: Wiley Computer Publishing.

Moos, R. H. (2002). The mystery of human context and coping: An unraveling of clues. American Journal of Community Psychology; 30(1), 67-88.

Nelson N.G., Dell'Oliver C., Koch C., \& Buckler R. (2001). Stress, coping, and success among graduate students in clinical psychology. Psychol Rep., 88, 759-67. 
Öngen, D. (2006). The relationships between coping strategies and depression among turkish. Social Behavior and Personality, 34(2), 181196.

Park CL, Armeli S, \& Tennen H. (2004). The daily stress and coping process and alcohol use among college students. J Stud Alcohol., 65(1), 126135.

Patterson, F., Lerman., C., Kaufmann, V.G., Neuner, G.A., \& AudrainMcGovern, J. (2004). Cigarette smoking practices among American college students: Review and future directions. J Am Coll Health., 52(5), 203-210.

Ratner, B. (2000). Chaid for interpreting a logistic regression model. Journal of Targeting, Measurement and Analysis of Marketing, 4, 16-29.

Rohde, P., Lewinsohn, P. M., Tilson, M., \& Seeley, J. R. (1990). Dimensionality of coping and Its relation to depression. Journal of Personality and Social Psychology, 58, 499-451.

Roth, S., \& Cohen, L. J. (1986). Approach, avoidance, and coping with stress. American Psychologist, 41, 813-819.

Seiffge-Krenke, I. \& Klessinger, N. (2000). Long-term effects of avoidant coping on adolescents' depressive symptoms. Journal of Youth and Adolescence, 29, 617-630.

SPSS Inc. (1998). AnswerTree user's guide.Chicago: SPSS Inc.

Şahin, N.H. ve Durak, A. (1994). Kısa Belirti Envanteri (Brief Symptom Inventory- BSI): Türk Gençleri İçin Uyarlanması. Türk Psikoloji Dergisi, 9(31), 44-56.

Türe, M., Kurt, İ., Kurum, AT., Özdamar, K. (2005). Comparing classification techniques for predicting essential hypertension. Expert Systems with Applications, 29, 583-8.

Türe, M., Aktürk, Z., Kurt, İ., Dağdeviren, N. (2006). Tümevarım Tekniği Kullanılarak Sağlık Durumu, Beslenme ve Bazı Diğer Faktörlerin Okul Başarısızlığına Etkisinin Araştırılması. Trakya Üniversitesi Tip Fakültesi Dergisi, Cilt 23(1), 28-38.

Vitaliano, P. P, Maiuro, R. D., Russo, J, \& Becker, J. (1987). Raw versus relative scores in the assessment of coping strategies. Journal of Behavioral Medicine, 10, 1-18. 